\title{
Knowledge and attitudes towards contraceptives among undergraduates in the state universities of Western Province
}

\section{Upuli Perera $^{1 *}$ \& Chrishantha Abeysena ${ }^{2}$}

${ }^{1}$ Office of the Regional Director of Health Services, Gampaha District, Sri Lanka; Department of Public Health, Faculty of Medicine, University of Kelaniya, Sri Lanka

${ }^{*}$ Correspondence: tauapp100@gmail.com (iD https://orcid.org/0000-0003-3177-6920

DOI: https://doi.org/10.4038/jccpsl.v25i2.8180

Received on: 4 October 2018

Accepted on: 29 May 2019

\begin{abstract}
Introduction: Contraceptives help prevent unplanned pregnancies and have the desired number of children with adequate space. Most undergraduates are living outside their home environment. Despite being more vulnerable to risk behaviour, their knowledge and attitude towards contraceptives are poor.
\end{abstract}

Objectives: To describe the knowledge and attitudes towards contraceptives among undergraduates in state universities of Western Province

Methods: Adescriptive cross-sectional study was conducted among 1575 second- and third-year undergraduates using stratified cluster sampling of the selected universities. A pre-tested self-administered questionnaire collected data on knowledge and attitudes on contraceptives. Based on a scoring system, the level of knowledge and attitudes was assesed. Their associations with selected variables were determined.

Results: Of the 1575 respondents, 926 (58.8\%) were females. Over 90\% were aware of at least one contraceptive method. More than 50\% knew that condoms are protective against HIV/AIDS. The knowledge on contraception was 'good' in $28.4 \%$. The knowledge on condom use was good in $21 \%$. In multivariate analysis, the only factor associated with good knowledge on contraceptives was studying in Bioscience stream (adj. OR $=9.5 ; 95 \% \mathrm{CI}=7.0$, 12.9), whereas the factors associated with good knowledge on male condoms were: being male (adj. $\mathrm{OR}=13.2 ; 95 \%$ $\mathrm{CI}=10.3,16.9$ ), studying in Bioscience stream (adj. $\mathrm{OR}=1.8 ; 95 \% \mathrm{CI}=1.1,1.9$ ) and secondary education in nonmixed type schools (adj. $\mathrm{OR}=1.4 ; 95 \% \mathrm{CI}=1.1,2.0)$.

Overall, 30.3\% $(n=477)$ and $38.6 \%(n=608)$ of the respondents had desirable attitudes towards contraception and male condoms, respectively. In multivariate analysis, factors associated with desirable attitudes on contraception were: being male (adj. $\mathrm{OR}=1.7 ; 95 \% \mathrm{CI}=1.4,2.2$ ), studying in Bioscience stream (adj. $\mathrm{OR}=1.5 ; 95 \% \mathrm{CI}=1.1,2.0$ ) and secondary education in non-mixed type schools (adj. $\mathrm{OR}=1.3 ; 95 \% \mathrm{CI}=1.1,1.7$ ), whereas the only factor associated with desirable attitudes on condom use was being male (adj. $\mathrm{OR}=3.4 ; 95 \% \mathrm{CI}=2.8,4.2$ ).

Conclusions: Knowledge and desirable attitudes towards contraceptives and condoms were relatively low among the undergraduates. Being female and studying in non-Bioscience stream were major determinants.

Key words: attitudes, condoms, contraception, knowledge, reproductive, undergraduates 


\section{Introduction}

Contraceptives help prevent unplanned pregnancies and have the desired number of children with adequate spacing while preventing pregnancy related health risk in women and infants. In addition, the male condom helps prevent HIV/AIDS (1).

According to the most recent Demographic and Health Survey, contraceptive use is relatively high among married youth in Sri Lanka (2). One study reported that the extent of awareness on family planning methods ranged from moderate to high $(63 \%$ to $84 \%$ ) in different age and marital groups (3). A study conducted in 2007 in Sri Lanka revealed that male undergraduates had better knowledge on contraceptive methods (77.5\%) compared to females (18\%) (4). Similar results have been observed in research done worldwide (5-6). A study conducted in Nigeria revealed that awareness on emergency contraceptive pills (ECP) among female undergraduates was as low as $50.7 \%$ (7). In another study among female undergraduates in Ethiopia, 84.2\% had never heard of ECPs, and the effectiveness and safety of the method were known only by $23.1 \%$ and $58.7 \%$, respectively (5).

Condoms are the only method of contraception that provide dual protection, i.e. protection from sexually transmitted diseases (STD) and pregnancy. Consistent condom use has been recognized as one of the most successful preventive strategies for HIV infection globally including in Sri Lanka. Condoms are widely available in Sri Lanka in STD clinics, family planning clinics, with public health midwives and in pharmacies island wide (8). Condoms were the most well-known contraceptive method (29\%) followed by pills (24\%) in Sri Lankan adolescents in 2004 (9). In comparison, one study reported that the knowledge on correct condom usage among adolescents in four African countries was very high (10). Further, a study reported a score of more than $75 \%$ for positive attitudes towards contraceptives among the undergraduates in Uganda (5). Unlike knowledge, studies on attitudes towards contraceptive methods are scarce in university students.

Students who perform well at Advanced Level examination are the ones selected to state universities, and the society expects them to give leadership to others in the country upon graduation for creating an economically stable and healthier nation. However, being of young age, they too are at higher risk of exposure to risky sexual behaviours. Exploring their knowledge and attitudes towards contraception would be beneficial in providing services targeting their needs. In the absence of recent data on knowledge and attitude towards contraceptives among Sri Lankan undergraduates, the objective was to describe the knowledge and attitudes towards contraceptive methods among undergraduates in the state universities of Western Province.

\section{Methods}

A descriptive cross-sectional study was conducted in all state universities in the Western Province of Sri Lanka, namely the University of Colombo, University of Sri Jayewardenepura, University of Kelaniya and University of Moratuwa. Students are enrolled to these universities according to the Advance Level $\mathrm{Z}$ score and comprise 32,200 in number according to the university statistics in 2011 (11). The study population consisted of undergraduates studying in second and third years in the universities. Undergraduates in the first year were excluded due to being less familiar with the new environment, and the fourth- and fifth-year students due to smaller numbers (other than in medical faculties). Undergraduates from foreign countries and undergraduates from the clergy were also excluded due to their different socio-cultural backgrounds and due to the sensitive nature of the selected subject. The calculated sample size was 1575 . A multi-stage stratified cluster sampling technique with probability proportionate to the size of each university population was carried out to select a representative sample of undergraduates. The details of the methodology are published elsewhere (12).

A self-administered questionnaire was used for data collection. It included one question on conception and nine questions on contraceptive methods (on awareness and the categorization of six methods as permanent and hormonal methods) to assess the overall knowledge on contraceptives. Knowledge on the use of condoms included five statements. One mark was given for each correct answer and zero marks for incorrect and 'do not know' answers. Awareness on where to obtain condoms from was assessed with questions on six instances. One mark was given for each correct place; maximum of two marks were awarded for total awareness. The overall knowledge on condoms was assessed using both parts. Total marks obtained were converted to percentages. If the obtained mark was more than $75 \%$, it was categorized 
as 'good' knowledge, $50-74 \%$ marks as 'satisfactory' knowledge, and less than $50 \%$ marks as 'poor' knowledge.

The attitudes towards contraceptives and condoms were separately assessed with five and eight statements, respectively. One statement contained five responses; strongly agree, agree, neutral, disagree and strongly disagree. Mark allocation was as follows: +1 for a desirable attitude; -1 for an undesirable attitude; and no marks for a neutral attitude. Obtained marks were added for a range of scores from -5 to +5 for contraceptives and from -8 to +8 for condoms. Total calculated marks were converted to percentages. Categorizations were done as follows: ? $75 \%$ of the total marks considered as desirable attitudes and others as undesirable attitudes. Associations of each category with selected variables were assessed with odds ratio (OR) and 95\% confidence interval (CI). Multiple logistic regression was applied to detect association.

\section{Results}

Of the 1575 who responded, 926 (58.8\%) were females and 1551 (98.5\%) were unmarried. Mean age was 23 years while $248(15.7 \%$ ) were in the Bioscience degree programme and $1082(68.7 \%)$ residing in university hostel or at a boarding place.

\section{Knowledge on contraception and male condoms}

A majority ( $\mathrm{n}=888 ; 56.4 \%)$ of respondents knew that pregnancy could occur even at the first sexual intercourse. Over $90 \%(n=1470)$ of the respondents were aware of one or more method of contraception. In terms of awareness on individual methods, the highest percentage $(\mathrm{n}=1419 ; 96.6 \%)$ was reported for oral contraceptive pills followed by condoms ( $\mathrm{n}=1404$; 95.6\%). Awareness on safe period, emergency pill and intrauterine device were $68.8 \%(\mathrm{n}=1012), 62.8 \%$ $(n=922)$ and 64\% $(n=948)$, respectively. Awareness on male sterilization was less $(\mathrm{n}=824 ; 56.1 \%)$ compared to female sterilization ( $\mathrm{n}=939 ; 63.9 \%$ ). Only $29.2 \%(\mathrm{n}=429)$ were aware of Depo-Provera injections, which was also the least known method. Further, $654(44.5 \%)$ correctly categorized oral contraceptive pill as a hormonal method, whereas it was only $17.2 \%$ $(n=253)$ for Depo-Provera. Around 40\% (42.2\% and $38.3 \%$ ) identified male and female sterilization as permanent methods, respectively. The awareness was poor $(n=417 ; 28.4 \%)$ on emergency contraceptive pills as a hormonal method.

More than $50 \%$ of the undergraduates knew that condoms are an effective means of protection against HIV/AIDS and they cannot be reused after washing (Table 1). Most ( $\mathrm{n}=1069 ; 67.9 \%)$ were aware about the places to obtain a condom. Pharmacy was the most commonly $(\mathrm{n}=1037 ; 65.8 \%)$ known place followed by family planning clinic $(\mathrm{n}=231 ; 14.7 \%)$.

\section{Table 1. Frequency distribution of accurate responses on given statements on male condoms $(\mathrm{N}=\mathbf{1 5 7 5})$}

\begin{tabular}{lc}
\hline Statement & $\begin{array}{l}\text { No. of accurate } \\
\text { responses (\%) }\end{array}$ \\
\hline $\begin{array}{l}\text { Condoms are an effective way of } \\
\text { protecting against HIV/AIDS. }\end{array}$ & $946(60.1)$ \\
$\begin{array}{l}\text { Condom should be used just } \\
\text { before ejaculation. }\end{array}$ & $769(48.8)$ \\
$\begin{array}{l}\text { Condom should be put on to the } \\
\text { penis before it erects. }\end{array}$ & $481(30.5)$ \\
$\begin{array}{l}\text { Incorrectly used condoms can be } \\
\text { burst in the vagina. }\end{array}$ & $598(38.0)$ \\
$\begin{array}{l}\text { Used condoms can be reused } \\
\text { after washing. }\end{array}$ & $878(55.7)$
\end{tabular}

With regards to knowledge on contraception, $28.4 \%(\mathrm{n}=447), 27.3 \%$ and $44.3 \%$ had good, satisfactory and poor knowledge, respectively. With regards to knowledge on male condoms, $52.9 \%(\mathrm{n}=833)$ had poor knowledge, $26.2 \%$ had satisfactory knowledge and $21 \%$ had good knowledge. Factors associated with good knowledge on contraceptives as well as on male condoms (Table 2) were: being male, studying in Bioscience stream and secondary education in nonmixed type schools. In multivariate analysis, only studying in Bioscience stream remained significant in relation to knowledge on contraceptives, while all three factors remained significant in relation to knowledge on male condoms, after adjusting for confounders.

\section{Attitudes towards contraception and condom use}

Of the attitudes on contraception, the one that suggested family planning for all couples scored the 
most $(n=1406 ; 89.7 \%)$, while the least scored was contraceptives not reducing sexual pleasure $(n=233$; $14.9 \%$ ) (Table 3 ). Of the attitudes towards male condoms, only two statements had scored more than $50 \%$ as a desirable attitude and of the remaining, two statements scored less than $20 \%$.

Overall, $30.3 \%(n=477)$ and $38.6 \%(n=608)$ of the respondents had desirable attitudes towards contraception and male condoms, respectively. Factors associated with desirable attitudes on both aspects (Table 4) were: being male, studying in the Bioscience stream and secondary education in non-mixed type schools. In multivariate analysis, all remained significant for attitudes on contraception and only being male for attitudes on male condoms.

\section{Table 2. Factors associated with overall knowledge on contraception and male condoms $(\mathrm{N}=1575)$}

\begin{tabular}{|c|c|c|c|c|}
\hline \multirow[t]{2}{*}{ Variable } & \multicolumn{3}{|c|}{ Knowledge No. (\%) } & \multirow{2}{*}{$\begin{array}{c}\text { Adjusted OR } \\
(95 \% \text { CI })\end{array}$} \\
\hline & Good & Satisfactory $^{1}$ & Poor $^{1}$ & \\
\hline Knowledge on contraception: & $(n=447)$ & $(n=430)$ & $(n=698)$ & \\
\hline \multicolumn{5}{|l|}{$\operatorname{Sex}^{2}$} \\
\hline Male & $200(31.0)$ & $196(30.4)$ & $249(38.6)$ & $1.2(0.9-1.6)$ \\
\hline Female & $246(26.6)$ & $234(25.3)$ & $446(48.2)$ & 1.0 \\
\hline \multicolumn{5}{|l|}{ Study Stream $^{3}$} \\
\hline Bioscience & $176(71.0)$ & $44(17.7)$ & $28(11.3)$ & $9.5(7.0-12.9)$ \\
\hline Art & $122(23.6)$ & $145(28.1)$ & $249(48.3)$ & 1.0 \\
\hline Commerce & $65(15.3)$ & $122(28.8)$ & $237(55.9)$ & \\
\hline Mathematics & $84(21.7)$ & $119(30.7)$ & $184(47.5)$ & \\
\hline \multicolumn{5}{|l|}{ School type ${ }^{3,4}$} \\
\hline Boys & $82(31.3)$ & $87(33.2)$ & $93(35.5)$ & $1.1(0.8-1.4)$ \\
\hline Girls & $102(29.6)$ & $99(28.7)$ & $144(41.7)$ & 1.0 \\
\hline Mixed & $184(28.5)$ & $158(24.5)$ & $303(47.0)$ & \\
\hline Knowledge on male condoms: & $(n=330)$ & $(n=412)$ & $(n=833)$ & \\
\hline \multicolumn{5}{|l|}{$\operatorname{Sex}^{2}$} \\
\hline Male & $266(41.2)$ & $254(39.4)$ & $125(19.4)$ & $13.2(10.3-16.9)$ \\
\hline Female & $64(6.9)$ & $158(17.1)$ & $704(76.0)$ & 1.0 \\
\hline \multicolumn{5}{|l|}{ Study Stream ${ }^{3}$} \\
\hline Bioscience & $72(29.0)$ & $65(26.2)$ & $111(44.8)$ & $1.8(1.1-1.9)$ \\
\hline Art & $61(11.18)$ & $113(21.9)$ & $342(66.3)$ & 1.0 \\
\hline Commerce & $67(15.8)$ & $124(29.2)$ & $233(55.0)$ & \\
\hline Mathematics & $130(33.6)$ & $110(28.4)$ & $147(38.0)$ & \\
\hline \multicolumn{5}{|l|}{ School type ${ }^{3,5}$} \\
\hline Boys & $131(50.0)$ & $88(33.6)$ & $43(16.4)$ & $1.4(1.1-2.0)$ \\
\hline Girls & $23(6.7)$ & $66(19.1)$ & $256(74.2)$ & 1.0 \\
\hline Mixed & $103(16.0)$ & $163(25.3)$ & $379(58.8)$ & \\
\hline Total & $330(21.0)$ & $412(26.2)$ & 833 (52.9) & \\
\hline
\end{tabular}

${ }^{1}$ For application of statistics, 'poor' and 'satisfactory' knowledge categories were amalgamated as 'less knowledge'; ${ }^{2}$ Missing data=4; ${ }^{3}$ Amalgamated as binary variables: study stream as Bioscience and non-Bioscience; school type as mixed and non-mixed schools. ${ }^{4}$ Missing data $=297 ;{ }^{5}$ Missing data $=323$ 
Table 3. Frequency distribution of the attitudes on contraception and condom use $(N=1575)$

\begin{tabular}{|c|c|c|c|}
\hline \multirow[b]{2}{*}{ Statement } & \multicolumn{3}{|c|}{ Attitudes No. (\%) } \\
\hline & Desirable & Neutral & Undesirable \\
\hline \multicolumn{4}{|l|}{ Attitudes on contraception: } \\
\hline $\begin{array}{l}\text { 1. Family planning is a good practice that should be1406( } 89.7) \\
\text { adopted by all the couples }\end{array}$ & $104(6.6)$ & $57(3.6)$ & \\
\hline 2. It is all right to make contraceptive methods available to unmarried & $1037(66.2)$ & $269(17.2)$ & $261(16.7)$ \\
\hline 3. Contraceptive methods do not lead to sub fertility & $451(28.8)$ & $866(55.3)$ & $250(16.0)$ \\
\hline 4. Contraceptives do not reduce sexual pleasure & $302(19.3)$ & $1031(65.8)$ & $233(14.9)$ \\
\hline $\begin{array}{l}\text { 5. Irrespective of the religion, using contraceptives is not a } \\
\text { sinful activity }\end{array}$ & $240(15.3)$ & $507(32.4)$ & $819(52.3)$ \\
\hline \multicolumn{4}{|l|}{ Attitudes on male condoms: } \\
\hline 1. A girl can suggest to her boyfriend to use a condom & $1077(68.8)$ & $347(22.2)$ & $142(9.1)$ \\
\hline 2. A boy can suggest to his girlfriend that he uses a condom & $1057(67.5)$ & $370(23.6)$ & $139(8.9)$ \\
\hline 3. Condoms are suitable for casual relationships & $776(49.6)$ & $536(34.2)$ & $254(16.2)$ \\
\hline 4. Condoms are suitable for steady, loving relationships & $626(40.0)$ & $567(36.2)$ & $373(23.8)$ \\
\hline $\begin{array}{l}\text { 5. It would not be too embarrassing for someone like me to } \\
\text { buy or obtain condoms }\end{array}$ & $685(43.7)$ & $408(26.1)$ & $473(30.2)$ \\
\hline $\begin{array}{l}\text { 6. If a girl suggested using condoms to her partner, it would not } \\
\text { mean that she didn't trust him }\end{array}$ & $315(20.1)$ & $450(28.7)$ & $801(51.1)$ \\
\hline 7. Condoms does not reduce sexual pleasure & 291(18.6) & $1054(67.3)$ & $22(14.1)$ \\
\hline $\begin{array}{l}\text { 8. The use of a condom by a male partner in a relationship is } \\
\text { not a sign of weakness or lessens their manhood }\end{array}$ & $76(4.9)$ & $525(33.5)$ & $964(61.6)$ \\
\hline
\end{tabular}

Table 4. Factors associated with overall attitudes on contraception and male condoms

\begin{tabular}{|c|c|c|c|}
\hline \multirow[t]{2}{*}{ Variable } & \multicolumn{2}{|c|}{ Attitudes No. (\%) } & \multirow{2}{*}{$\begin{array}{c}\text { Adjusted OR } \\
\text { (95\% CI) }\end{array}$} \\
\hline & Desirable & Undesirable $^{1}$ & \\
\hline Attitudes on contraception: & $(n=477)$ & $(n=1089)$ & \\
\hline \multicolumn{4}{|l|}{$\operatorname{Sex}^{2}$} \\
\hline Male & $239(37.3)$ & $401(62.7)$ & $1.7(1.4-2.2)$ \\
\hline Female & $236(25.6)$ & $686(74.4)$ & 1.0 \\
\hline \multicolumn{4}{|l|}{ Study Stream ${ }^{3}$} \\
\hline Bioscience & $94(38.2)$ & $152(61.8)$ & $1.5(1.1-2.0)$ \\
\hline Art & $152(29.5)$ & $364(70.5)$ & 1.0 \\
\hline Commerce & $107(25.3)$ & $316(74.7)$ & \\
\hline Mathematics & $124(32.5)$ & $257(67.5)$ & \\
\hline
\end{tabular}


(Table Ctd.)

\begin{tabular}{|c|c|c|c|}
\hline \multirow[t]{2}{*}{ Variable } & \multicolumn{2}{|c|}{ Attitudes No. (\%) } & \multirow{2}{*}{$\begin{array}{c}\text { Adjusted OR } \\
\text { (95\% CI) }\end{array}$} \\
\hline & Desirable & Undesirable $^{1}$ & \\
\hline \multicolumn{4}{|l|}{ School type $e^{3,4}$} \\
\hline Boys & $106(40.6)$ & $155(59.4)$ & $1.3(1.1-1.7)$ \\
\hline Girls & $100(29.3)$ & $241(70.7)$ & 1.0 \\
\hline Mixed & $182(28.3)$ & $461(71.7)$ & \\
\hline Attitudes on male condoms: & $(\mathrm{n}=608)$ & $(\mathrm{n}=957)$ & \\
\hline \multicolumn{4}{|l|}{$\operatorname{Sex}^{2}$} \\
\hline Male & $358(58.9)$ & $285(29.8)$ & $3.4(2.8-4.2)$ \\
\hline Female & $250(27.1)$ & $672(72.9)$ & 1.0 \\
\hline \multicolumn{4}{|l|}{ Study Stream ${ }^{3}$} \\
\hline Bioscience & $98(39.8)$ & $148(60.2)$ & $1.1(0.8-1.4)$ \\
\hline Art & $167(32.4)$ & $348(67.6)$ & 1.0 \\
\hline Commerce & $157(37.1)$ & $266(62.9)$ & \\
\hline Mathematics & $186(48.8)$ & $195(51.2)$ & \\
\hline \multicolumn{4}{|l|}{ School type ${ }^{3,4}$} \\
\hline Boys & $154(59.2)$ & $106(40.8)$ & $1.3(1.0-1.7)$ \\
\hline Girls & $92(27.0)$ & $249(73.0)$ & 1.0 \\
\hline Mixed & $230(35.8)$ & $413(64.2)$ & \\
\hline
\end{tabular}

${ }^{1}$ For application of statistics, 'poor' and 'undesirable' attitudes categories were amalgamated as 'undesirable'; ${ }^{2}$ Missing data $=4 ;{ }^{3}$ Amalgamated as binary variables: study stream as Bioscience and non-Bioscience; school type as mixed and non-mixed schools; ${ }^{4}$ Missing data $=321$

\section{Discussion}

Our study revealed that only $28.4 \%$ had good knowledge on contraception, while studying in Bioscience stream was a significant factor associated with it. Further, only $30.5 \%$ displayed desirable attitudes towards contraception, which was significantly associated with being male, studying in Bioscience stream and secondary education in non-mixed type schools.

A Sri Lankan study conducted in 2007 revealed that male undergraduates $(77.5 \%)$ possessed a good knowledge on contraceptive methods while female undergraduates (18\%) displayed a low level of knowledge (4). The present study also revealed that males had better knowledge on contraceptive methods than female undergraduates, but this difference was not significant. Good knowledge on contraceptives was reported by $43 \%$ of garment factory workers (13).
Undergraduates' knowledge is assumed to be higher than that of garment factory workers. However, this difference could also be due to the different methods of assessment of knowledge. Garment factory workers may also represent different backgrounds, for example participants may be living together or married, having more learning opportunities on family planning and/or reproductive health related matters in workplace etc.

De Silva (2008) has reported that the extent of awareness on family planning methods range from moderate to high ( $63 \%$ to $84 \%)$ in different age groups among adolescents (3). According to the current study, more than $93 \%$ of the undergraduates knew at least one method of contraception. Pills were the commonly known method (96.6\%) followed by condoms (95.6\%). According to the UNICEF National Survey, using condoms was the predominantly known method $(29 \%)$ followed by pills (24\%) (9). Undergraduates' 
knowledge on contraception is shown to be better than that of the overall adolescents in the country and the ten-year gap between them may be the cause for this difference.

Almost all undergraduates in a university of Uganda were familiar with some method of contraception though only one fifth knew about female condoms. As in the current study, the most commonly known methods were the oral contraceptive pills and male condoms (6). In another study among undergraduates in Ethiopia, 89.4\% were aware of modern contraceptives such as pills (64.8\%) and condoms (56.8\%) (14). In contrast, one Iranian study reported low knowledge on contraceptive usage among adults (15). In the current study, awareness on emergency contraceptives was $62.8 \%$. One study revealed a lower percentage $(43.5 \%)$ among female undergraduates from a university in Ethiopia (16). Though the level was $50.7 \%$ in female undergraduates in a Nigerian university (7), female undergraduates in Ethiopia had a relatively high awareness (84.2\%) (5).

Good knowledge on the use of condoms among undergraduates was only $21 \%$, which was much lower than expected. Males had better knowledge than females. Further, majority (61.2\%) of the respondents had an undesirable attitude towards male condoms. In comparison, the knowledge on condom usage has been detected to be relatively high in four African countries (10). Males had higher knowledge than females as in our study. Discrepancy of the results may be due to the assessment of different populations in the two studies. In addition, being in African countries with high prevalence of HIV/AIDS their knowledge may be greater than ours.

Condoms are the only method of contraception that provide protection from STIs and pregnancy. Consistent condom use has been recognized as one of the most successful prevention strategies for STIs prevention including HIV, globally (8). In consistent with the current study, a negative attitude towards condom was reported among young unmarried Indian males (17).

The results of this study are based on a representative sample of four state universities in the Western Province, and therefore the selection bias is minimal. A qualitative study is recommended to assess in-depth knowledge and attitude towards contraceptives and condoms.

\section{Conclusions \& Recommendations}

Good knowledge and desirable attitudes towards contraceptives and the use of condoms were low. Male Students and those studying Bioscience contributed to good knowledge as well as desirable attitudes towards contraceptives and condoms.

\section{Public Health Implications}

As the knowledge and desirable attitude towards contraception including condoms are relatively low, undergraduates comprise a high-risk group for risky sexual behaviour. It should be improved for achieving reproductive health among them and for future generation.

\section{Author Declarations}

Competing interests: The authors declare that they have no competing interests.

Ethics approval and consent to participate: Ethical approval was obtained from the Ethical Review Committee of the Faculty of Medicine, University of Kelaniya (P202/12/2013). Informed written consent was obtained from participants.

Funding: The Medical Research Institute of the Ministry of Health, Sri Lanka funded for the data collection of the study.

Acknowledgements: All the undergraduates who participated in the study and the staff of the universities, data collectors and the members of the Board of Study in Community Medicine, Postgraduate Institution of Medicine.

Author contributions: Both authors have contributed equally to the design the study. UP and CA analysed and interpreted the data. UP was responsible for the conduct of the literature review and implementation of study and a major contributor in writing the manuscript. All authors read and approved the final manuscript. 


\section{References}

1. WHO. Global incidence and prevalence of selected curable sexually transmitted infections - 2008. Geneva: World Health Organization, 2012.

2. DCS. Sri Lanka Demographic and Health Survey 2006/7 Preliminary Report. Colombo: Department of Census and Statistics, 2008.

3. De Silva WI, Somanathan A, Eriyagama V. Adolescent and Youth Reproductive Health in Sri Lanka. Status, Issues, Policies and Programs. Health Policy Programme, Institute of Policy Studies in Sri Lanka, Colombo, 2003.

Available from: http://www.policyproject.com/pubs/ countryreports/ARH_Sri_Lanka.pdf.

4. Herath HMRP, Dissanayake DMAB, Hilmi MAM, Pathmeswaran A, Wijesinghe PS. Adolescent sexual practices and contraceptive usage. A collection of research papers on adolescent sexual and reproductive health. Faculty of Medicine, University of Kelaniya, 2008; 171-195.

5. Ahmed FA, Moussa KM, Petterson KO, Asamoah, BO. Assessing knowledge, attitude, and practice of emergency contraception: a cross-sectional study among Ethiopian undergraduate female students. BMC Public Health 2012; 12: 110.

6. Nsubuga H, Sekandi JN, Sempeera H, Makumbi FE. Contraceptive use, knowledge, attitude, perceptions and sexual behaviour among female University students in Uganda: a cross-sectional survey. BMC Women's Health 2016; 16: 6.

7. Akani CI, Enyindah CE, Babatunde S. Emergency contraception: knowledge and perception of female undergraduates in the Niger Delta of Nigeria. Ghana Medical Journal 2008; 42(2): 68-70.

8. National STD/AIDS Control Programme. Situation assessment of condom programming in Sri Lanka. Colombo: Ministry of Health \& United Nations Population Fund, 2015.

9. Thalagala N \& Rajapaksa, L. National Survey on Emerging Issues among Adolescents in Sri Lanka. Colombo: UNICEF, 2014.
10. Bankole A, Ahmed FH, Neema S, Ouedraogo C, Konyani S. Knowledge of correct condom use and consistency of use among adolescents in four countries in Sub-Saharan Africa. African Journal of Reproductive Health 2007; 11(3): 197-220.

11. University Grants Commission. Sri Lanka University Statistics, 2011.

Available from: http://www.ugc.ac.lk/en/statistics/ university-statistics-2011.html

12. Perera UAP \& Abeysena C. Prevalence and associated factors of risky sexual behaviours among undergraduate students in state universities of Western Province in Sri Lanka: a descriptive crosssectional study. Reproductive Health 2018; 15: 105.

13. Sirimanne STD. Knowledge, attitude and practices of some components of reproductive health among female garment factory workers in the $\mathrm{MOH}$ area Polgahawela. MSc Dissertation (Community Medicine). Colombo: Postgraduate Institute of Medicine, 2006.

14. Yared A, Sahile Z, Mekuria M. Sexual and reproductive health experience, knowledge and problems among university students in Ambo, Central Ethiopia. Reproductive Health 2017; 14: 41.

15. Khajehei M, Ziyadlou S, Ghanizadeh A. Knowledge of and attitudes towards sexual and reproductive health in adults in Shiraz: a need for further education. Eastern Mediterranean Health Journal 2013; 19(12): 982-989.

16. Enqueselassie F \& Tamire W. Knowledge, attitude, and practice on emergency contraceptives among female university students in Addis Ababa, Ethiopia, Ethiopian Journal of health Development. 2007; 21(2): 111-116.

17. Meena JK, Verma A, Kishore J, Ingle GK. Sexual and Reproductive Health: Knowledge, attitude, and perceptions among young unmarried male residents of Delhi. International Journal of Reproductive Medicine 2015; 431460.

Available from: http://dx.doi.org/10.1155/2015/431460. 